\title{
Satisfaction with valuable realization of requirements by spiritual personality counterbalances psyche
}

\begin{abstract}
Requirements share on necessary for any to live, and spiritual which are necessary for knowledge of the world around, knowledge acquisition and abilities, achievement of harmony and beauty. Requirement is a psychological function which motivates to act, giving the purpose and the direction to behavior. It is the experienced and realized need or need. The mentality of the person is very closely connected with his requirements. Needs of the personality are a source of activity of mentality. The activity of mentality is shown in the course of satisfaction of requirements with the person. The satisfaction of requirements depends on situations and living conditions. An opportunity or impossibility to realize the needs for concrete situations and living conditions defines either satisfaction, or dissatisfaction of the person that as a result forms a condition of mentality. Development of people is followed by process of satisfaction of their requirements. If people meet the need in food thanks to crop production and livestock production, then the satisfaction of spiritual thirst requires higher level of public self-knowledge. If the person couldn't satisfy requirement, he becomes uncertain, and his mentality unbalanced. The satisfaction with realization of necessary requirements counterbalances psyche.
\end{abstract}

Volume 7 Issue 6 - 2018

\author{
Evgeniy Bryndin \\ Research center "ESTESTVOINFORMATIKA", Russia
}

Correspondence: Evgeniy Bryndin, Research center "ESTESTVOINFORMATIKA", Novosibirsk, Russia, Email brymdin 15@yandex.ru

Received: October 23, 2018 | Published: November 16, 2018

Keywords: mentality, requirement, satisfaction, reason, will, desire, motivation, psyche

\section{Introduction}

The satisfaction is a positive mental state. The constant satisfaction is a state and a key indicator of balanced mentality. Experimental tests and social polls show that the people satisfied with realization of necessary material and cultural requirements have balanced mentality. The long-term satisfaction promotes formation of balanced mentality. Realization of necessary requirements makes positive impact on mentality. The satisfactory result of realization counterbalances mentality. Realization of requirements dynamically depends on social and material conditions. Material and social aspects it is key factors which operate dynamics of satisfaction of the person. Researches of complex dynamics of satisfaction in the sphere of cultural and material needs for social conditions and also cumulative results of realization of requirements, show dynamics of a condition of his mentality (soul). Not everything is pleasant to all and not at all to everything soul equally lies, but one have more to one, and others have more to another. It is expressed so: every man to his taste. It depends partially on natural predisposition, partially on the first impressions, on impressions of education and accidents of life. Tastes force the person suit so the life, such to surround itself with objects and ratios what specify his taste and with what is laymen he, being satisfied with them. The satisfaction of tastes of soul gives him tranquility which makes a measure of balanced mentality. Nothing disturbs - here and tranquility. If the person always in a mental part sticks to judiciousness, and in activity - prudence, then would meet the smallest share of the cases unpleasant to his soul in life, and, therefore, would have the greatest share of satisfaction and tranquility.

\section{Consciousness will and feelings in satisfaction of requirements}

Acts of consciousness don't happen isolated, the thought is always followed by feeling, feeling and will — a thought, and feeling — the strong-willed movements; acts of will are always connected with feeling and thoughts; the complex of these at the same time proceeding acts of consciousness defines a condition of consciousness. These conditions of consciousness incessantly change because acts of consciousness are in the continuous movement. Wealth, a variety and depth of acts and conditions of consciousness, the consciousness volume which is also constantly changing usually towards increase is defined. Our soul always participates in acts and conditions of consciousness, defining and directing them. In turn, soul changes from consciousness activity, from his separate acts and states. The will which wishes to get, use or make that it finds useful to itself, either necessary, or pleasant is using the force. Desire always has the certain subject satisfying requirement. With awakening of will also different desires are born: that, another, the third subject able to satisfy requirement. To the person predlezhit the choice to what subject to give preference. After the choice there is a decision - to make, either to get, or to use the favorites. After the decision selection of means becomes and the way and an order of execution is defined. It is followed, at last, by business in due time and in the place. "We have to give three strength of soul the movement correct, corresponding to their nature and concordant with intention of God who has created them force irritable needs to be moved against our external person and against the enemy of mankind of a Satan Sill desirable should direct to God and virtue, and mental we will put madam over both of them that with wisdom and prudence I ordered them, I talked some sense, I punished and I commanded over them as the tsar commands over citizens. Truly speaking, any lawlessness and a sin by these three forces become, and any virtue and the truth are made by the same three forces" (Saint Isikhy, the presbyter Jerusalem). Forces of soul are generated by her energy (mental energy). Mental energy realizes abilities of soul: ability to feel heart (as spiritual substance), ability to think of mind, ability to execute the made decisions will. Respectively, feelings, thoughts and strong-willed acts, are result of mental energy. Heart, mind and will as mental abilities of soul, create the harmonious mental system of the person as God's special creation - the God's creation wreath. 
Soul through sensual heart creates moral mental energy, through mind creates substantial mental energy, will connect moral and substantial mental energy and enables her moral and substantial realization. Feelings of the person are characterized by spiritual orientation. Where your heart, that is to what your feelings and desires are directed, will be there and the treasure is higher. The orientation of heart, orientation of feelings and desires, is defined by what is pleasant to the person to what heart lies at him that he loves. For example, the person can love God and the neighbor, carrying out thereby two main God's precepts. At the same time the spiritual orientation of the person true, it conducts him to God. On the other hand, the person can love worldly: the power, glory, carnal joys, wealth. In this case the spiritual orientation of the person is sinful, it takes away him from God. Because "friendship with the world is hostility against God! So, who wants to be a friend to the world, that becomes enemy God" (James. 4: 4). Who loves the world, in that there is no love God; because everything that in the world: the lust of flesh, lust of eyes and pride every day, isn't from the Father, but from (this) world ...' (1 John. 2: 15-17). The religious philosopher S.L. Frank writes: "The person by the nature belongs to two worlds - to God and the world; his heart is connection point of these two forces. He can't serve these two forces ... at once". What force will prevail in the person, there he also will go, to God or from Him. Our Lord and the Savior Jesus Christ says: Nobody can serve two misters: because or one will hate, and another to love; or to one will begin to be zealous, and not to take care of another. You can't serve God and a mammon (Matthew 6:24). The mind is characterized by endowments, talent and even genius and also has spiritual focus. The endowments of mind are that (as thinks) the person how exactly thinks how effectively he can expect results of the actions and find solutions of objectives. The spiritual orientation of mind is in what direction he thinks: about heavenly or about terrestrial; about that how to execute God's willed (the God's precept) or how to grant the lewd desires; about that how to gain the Holy Spirit or how to get material benefits (that is about the one to whom to serve: To god or mammon). The same person can have at the same time gifted mind by cogitative criterion and to be sinful - on spiritual and to be "evil genius". The term "will" matters the certain force directed to achievement of a main objective - obtaining target pleasure. The will is a conscious aspiration to implementation of the purpose or objectives or ability (ability, determination) to carry out the desires. The will, as well as other mental abilities, is characterized by two parameters: by force and spiritual orientation. Different people have various will powers. One people are called strong-willed, that is, having strong willed (big will power). These people follow commands of reason, overcoming various obstacles in the way, in particular, inhibiting in itself desires (influence of feelings) which realization hinders rational achievement of the goal (distracts from approach to the purpose). Other people are called weak-willed, that is, having weak will. Such people, knowing that this action shouldn't be done (or on the contrary, it is necessary to do), less do those it (or on the contrary, don't do what is necessary). Then they regret for it, but again arrive also, again regret, etc. So for example, if the person, understanding sinfulness of an act, makes it or, understanding that it is necessary to do good and knowing that the Lord demands from us, doesn't do it, then the lack of will is shown here. And then he becomes the slave to a sin as does not that wants not that he considers reasonable and necessary, and what wants and considers reasonable and necessary doesn't do. The spiritual orientation of will is caused by where she conducts the person: to God or from Him.
Feelings make a strategic basis of the person. On the basis of feelings, the feeling more precisely resulting, strategic (the main, final) the purpose is also chosen. The person will seek to that (to wish that) that is pleasant to him more (gives more pleasures, happiness, pleasure), taking into account the expected consequences, including in the form of a remorse, and some other factors. "The aspiration fortunately, to pleasure is put in the person Bogy. Desire of God eternal pleasure of the person that as the proof serves the human nature which is constantly wishing and aspiring only to pleasant in life, and hating and constantly wishing to will evade from all unpleasant". "The person is created Bogy at the beginning blissful and for pleasure, thus eternal. The person is happy or unhappy the feelings: one act as the pleasant component, others - unpleasant, depending on degree of satisfaction of the corresponding requirement" (Amosov N. M.). The principle (the main or strategic mental basis), general for all people, is the aspiration to the highest happiness - pleasure or "a strategic treasure". At the same time for various people is available also basic difference in type of this pleasure. One people look for pleasure terrestrial, others - pleasure heavenly. Each person, according to the taste, will seek to the treasure (to wish the treasure). Only for one of this treasure there will be earthly goods, terrestrial glory about which transience the Saint apostle Peter writes, and for others - the heavenly benefits, heavenly glory for which so brightly and so clearly the Saint apostle Paul and the Reverend Seraphim of Sarov call, for example. In the world people often, or even generally strive for harmful pleasure. Namely to pleasure in power, to pleasure in glory, to pleasure in wealth, to pleasure in satisfaction of the lewd desires. Thus, the power, glory, wealth, lewd pleasures become peculiar gods for the person, their belief and hope. Respectively at the person also the love to these false gods develops: love power, glory, silver. And he we become their slaves.

The prelate John Chrysostom writes: "If the Kingdom of Heaven is opened for us and requital in future life is shown, then already to you it isn't necessary and to investigate why just stand grief's here, and vicious live in pleasures. Because if there the award on merits expects everyone, then for what to be indignant with the local events happy and unfortunate? These disasters God obedient to Him exercises as courageous fighters, and weaker, careless and not able to transfer nothing heavy previously talks some sense on good deeds". Christian teaching about the Kingdom of Heaven is the doctrine about the place of pleasure, prepared for believers in the Lord and loving him. Jesus Christ learns and warns us: "Don't collect to yourself treasures on the earth where mol and a rust exterminate and where thieves undermine and steal, but collect to yourself treasures in the sky where neither the mol, nor a rust exterminate and where thieves don't undermine and don't steal" (Matthew. 6: 19, 20). True education of the feelings which are a strategic basis of development of the person in general and highquality improvement and equilibration of his mentality, in particular. ${ }^{1-3}$ The mind of the person decides how to achieve the objectives in the rational way, that is chooses a way of achievement of the goal, determined by feelings. "Reason - the servant of heart" - Saint John of Kronstadt says. Feelings have very strong influence on character and focus of thinking and all behavior of the person" - the archpriest Nikolay Malinovsky writes. The orientation of mind is defined by orientation of feelings. The mind has ability to expect results of the activity and ability to find solutions of realization of requirements on the basis of the available experience and taking into account different types (physical; material; moral, including satisfaction) estimated 
consequences. It also allows defining the best options of the current actions, both for the solution of realization of requirements, and for activity in general. The will provides the movement to realization of requirements, way which has chosen reason. At the same time action of will is directed to overcoming barriers on the way of their realization and also on satisfaction with realization of a way of the behavior chosen as reason. Generally, psychologically, feelings define the purpose (that needs to be realized), the reason defines ways and means of achievement of the purpose chosen as feelings (as it is necessary to realize requirement), the will provides the movement to the purpose on the way chosen as reason helps to realize requirement. The most significant, basic requirements define orientation of all mentality of the person - his feelings, thinking, will. If the person is excessively creative and doesn't represent the life without creativity, then it and the most important requirement for the personality

\section{The valuable realization of requirement counterbalancing mentality}

Requirements are in deep communication with outlook and the system of values. The system of values focuses the personality on this or that strategy of vital behavior. The system of values is set of estimates by the person of objects and phenomena of the world around - directly indicates how it is necessary to treat the existing requirements how it is necessary to form them and to correct. Value is assessment of the phenomena and events as I am kind or angry, useful or harmful, fine or ugly, admissible or forbidden, fair or unfair, etc. The possibility of comparison of the world around to requirements and values of the person with a brilliant accuracy is painted in an aphorism of the Ancient Greek sophist Protagor (490 - 420 BC): "The person is a measure of all things". In this statement valuable approach to the world is brightly shown. Requirements and values penetrate literally all spheres of public life, all social structures and the relations. Requirements and values act as an important link between society, the social environment and the individual, the personality, her inner world. Values represent beliefs of people about life and acceptable behavior. Moral value is acceptance on itself responsibility for the acts. Cultural wealth, love, the truth, good and beauty, are values of spiritual life of the personality. The spirituality - is internal installation of the individual to work according to the conscience. Spiritual life of society is inconceivable without connection of spiritual production and spiritual consumption. Nobody will be able to enjoy music which isn't created! In spiritual life of society the activity directed to creation, preservation and distribution of cultural wealth spiritual needs and spiritual consumption represents indissoluble unity. Spiritual consumption is a special kind of activity and, therefore, it has the focus, demands certain efforts, use of appropriate means. In the course of spiritual consumption as means of achievement of the goal material resources, perform with another the corresponding knowledge and skills, on the one hand, (to read the book, it is necessary to have an opportunity to receive it in library or to buy.) The education level and the general culture of the personality directly influence consumption of cultural wealth. Spiritual needs of the person represent internal motives to creativity, creation of cultural wealth and their development, to spiritual communication. Spiritual needs are set socially. This requirement in itself doesn't arise. It has to be created and developed by a social context, the individual's environment in difficult and long process of his education and education.
At the same time at first society form only the most elementary spiritual needs providing his socialization at the person. Spiritual needs of higher order - development of richness of world culture, participation in their creation, etc. - society can form only indirectly, through the system of the cultural wealth serving as reference points in spiritual self-development of individuals. Spiritual needs have essentially unlimited character. Limits of growth of requirements of spirit don't exist. Only volumes of the spiritual riches which are already saved up by mankind, opportunities and the power of desire of the person to participate in their production can act as natural limiters of such growth. Spiritual activity is a basis of spiritual human life and society. Spiritual activity - a form of the active relation of human consciousness to the world around of which are result: a) the new ideas, images, representations, values which are embodied in philosophical systems, scientific theories, works of art, moral, religious, legal and other views; b) spiritual public relations of individuals; c) the person. Ideal educations as a product of spiritual activity and production have the general nature of their consumption. Any spiritual value ideally can be property of all. From consumption they don't decrease as material, on the contrary, than more people seize cultural wealth, that high probability of their increment. Special type of spiritual activity is distribution of cultural wealth for the purpose of assimilation by their perhaps large number of people. The special role belongs to institutions of science, culture, church, education systems and education here. Cultural wealth - the category indicating human, social and cultural value of various spiritual educations (the ideas, theories, images) considered in the context of "good and evil", "the truth or a lie" "fine or ugly", "fair or unfair". In cultural wealth the public nature of the person and a condition of his life is expressed. The person is a being spiritual, a part of the inner world created by God. The person allocated with ability to feel spiritual needs more precisely and better perceives the world around in all its variety. Such person easier and quicker understands that the behavior coinciding with moral standards except other gives feeling of emotional satisfaction and internal tranquility makes balanced psyche.

\section{Conclusion}

To be favorable by the spiritual person. Clever desire and a kind thought are born in the soul from love for God. Only the person allocated with a possibility of achievement of God's similarity has a balanced and perfect system of mental forces (hearts, mind, will) and their manifestations (feelings, thoughts, strong-willed acts). This magnificent system is property of human mentality. Her basic feature is the moral and spiritual orientation. Bringing up and leaning on true moral and spiritual desires of people it is capable to reach balanced mentality in realization of necessary material and spiritual needs..$^{48}$

\section{Acknowledgements}

None.

\section{Conflict of interest}

The author has no conflicts of interests in this work.

\section{References}

1. Vekker LM. Mentality and reality: uniform theory of mental processes. M Sense. 2000:685.

2. Bryndin EG. Way to godlike perfection. Germany: LAMBERT Academic Publishing; 2015:205. 
3. Bryndin EG. Spiritual regularities of state of mind. II International scientific conference "Theological measurement of the present: philosophy and sociology of religion; Saratov: SGU; 2016:44.

4. Bryndin EG, Bryndina IE. Normalization of Psyche by Healthy Lifestyle of Various Groups of the Population. American Journal of Applied Psychology. 2017;6(4):51-56.

5. Bryndin EG. Spiritual bases of wellbeing. Germany: LAP LAMBERT Academic Publishing; 2017:141.
6. Bryndin EG. Psychological and social aspects of formation of thinking, consciousness and behaviour. Scientific. Psychology of the Person as Subject of Knowledge, Communication and Activity. 2018.

7. Bryndin EG. Spiritual, Social, Economic and Healthy Aspects of Global Wellbeing. "The European Proceedings of Social \& Behavioural Sciences EpSBS. 2017:97-111.

8. Bryndin EG. Psychological and Social Aspects Formations of Thinking, Consciousness and Behavior. SM Physical Medicine \& Rehabilitation. 2018;2(1):1-5. 